\title{
Application of ANN in Hydraulic Pressure Control Fault Diagnosis System
}

\author{
Zhang Xiaoyu \\ The Department of Aeronautics Ammunition Engineer \\ The First Aeronautics College of Air Force \\ Xinyang, Henan, China \\ e-mail: zxydyx1024@126.com
}

\author{
Ding Lili \\ The Department of Aeronautics Ammunition Engineer \\ The First Aeronautics College of Air Force \\ Xinyang, Henan, China \\ e-mail: lilac6212@sina.com
}

\begin{abstract}
The existing hydraulic pressure control fault diagnosis system is effective on fault detection, but the fault isolation capability is bad. In order to improve the capability of the fault isolation, the artificial neural network (ANN) is used in the fault diagnosis system. Aimed at the representative diagnosis of the hydraulic pressure control system, the three layers feedback network is adopted, the basic theory of conjugate gradient BP neural network is explained in detail, and the key techniques are introduced. Five types of typical faults of hydraulic pressure control system can be distinguished easily by it, the faults diagnosis efficiency is higher $30 \%$ than ever and the fault diagnosis capability is better $80 \%$ than before.
\end{abstract}

Keywords-ANN; fault diagnosis; fault isolation; Hydraulic pressure control system; feedback

\section{INTRODUCTION}

The artificial neural network (ANN) developed in recent years has very high nonlinear mapping capability. Through learning, the ANN can approach to the researched object at discretion precision, which has high efficiency for faults isolation; at the same time, the ANN theory has many advantages such as self-study, self-organize, self-adaptation and self-correction, ANN has been used in many domains successfully [1-2].

The changes of the system state must be reflected by the changes of its dynamic characteristic; the essential of fault diagnosis is that the real time states of the diagnosed object can be distinguished in the time region. The hydraulic pressure control system faults diagnosis system of some kind airplane accomplish to test and isolate the faults based on the equivalence space method. This method can be used to test the faults effectively, but the faults isolation capability is bad.

Based on the ANN, the hydraulic pressure control faults diagnosis system of some kind airplane is improved. And the faults isolation performance is enhanced very much.

\section{FAULTS DIAGNOSIS THEORY BASED ON ANN}

The ANN is a nonlinear system which is connected by a great lot of simple process units, which has self-study, selforganize, self-adaptation and self-correction capacity. On the mapping point of view, the target of the faults diagnosis is the mapping from symptoms to faults types. Based on the ANN technology, the faults diagnosis system can not only recognize the complicated fault diagnosis modes, but also evaluate the faults penetrance and forecast faults. At the same time, the ANN can automatically acquire the faults knowledge, so the faults diagnosis system has self-adaptation capacity. When the BP neural network is used to diagnose faults of the some kind hydraulic pressure control system, some peak values of typical signal frequency charts are treated as the input samples, the network is studied by using $\mathrm{BP}$, the mapping relationship between the input samples (character signals) and the output samples (faults types), then faults can be diagnosed by the association memories and distribution processing of the neural network.

\section{STRUCTURE OF BP}

The BP neural network is a kind of multilayers feedback network, which includes an input layer, an output layer and some latent layers. These layers are connected by weight modulus. The convert function of latent layers is nonlinear function, such as function $\mathrm{S}$, so the send outs are consecutive numbers between 0 and 1 , the random nonlinear mapping between input and output can be come true[3].

The current faults symptoms are matched to the correlative rules of the latent layers by BP neural network, the relevant faults diagnosis results are obtained.

Suppose that there are $\mathrm{n}$ nerve cells in the system input layer, such nerve cells can receive $\mathrm{n}$ input signals $X_{1} \sim X_{\mathrm{n}}$. There are $\mathrm{m}$ nerve cells in output layer, which can bring $\mathrm{m}$ output signals $F_{1} \sim F_{\mathrm{m}}$. There are $M$ nerve cells $R^{1} \sim R^{\mathrm{M}}$, which correspond to $M$ samples one by one. The weight modulus between the input layers and latent layers are $\omega_{\mathrm{Ki}}$ ( $i=1 \sim \mathrm{n}$ ), they can show the essentiality of each faults symptom $X_{\mathrm{i}}$ to such sample $R^{\mathrm{k}}$; The weight modulus between the output layers and latent layers are $C_{\mathrm{jK}}(j=1 \sim m)$, they can show the essentiality of sample $R^{\mathrm{k}}$ to each faults $F_{\mathrm{j}} . \omega_{\mathrm{Ki}}$ and $C_{\mathrm{jK}}$ meet such equations as (1) and (2).

$$
\begin{gathered}
\sum_{i=1}^{n} \omega_{k i}=1 ; \omega_{k i} \geqslant 0 \\
\sum_{K=1}^{M} c_{j K}=1 ; c_{j K} \geqslant 0
\end{gathered}
$$




\section{SySTEM SOFTWARE DESIGN}

The program design is the key of the software. It is composed of the operation system platform, the application program development platform, and the fault diagnosis application program.

\section{A. Operation System Platform}

The operation system platform is the basic platform of the program soft development platform and fault diagnosis program [4-5]. Its capabilities will directly influence the fault diagnosis system's function and capability. The Windows NT platform is adopted as the software system. The Windows NT has many advantages such as simple, high reliability, high security and strong compatibility and so on. So it is adopted as the preferred operation platform to manage the whole software and hardware.

\section{B. Application Program}

The Lab Windows/CVI 5.0 of the NI Company is adopted as the application program development platform. The Lab Windows/CVI is the dummy instrument software development platform which faces to computer test control realm. The most important trait of it is that there are GPIB, VXI, series-wounded interface and function database of the insert mode DAQ board within it. And it can provide every kind of flexible and convenient interface creation, program and debugging tool, so it can greatly reduce the workload of program. However, it also has advanced analysis database with rich content, and it can do much work, for example, signal disposal, statistic, curved surface simulation synthesization and complicated analysis. At the same time, in order to make up some disadvantage of the Lab Windows / CVI, Windows SDK has been used, Photoshop, and Visual $\mathrm{C}++$ software to complete some accessorial work.

\section{Fault Diagnosis Application Program}

According to the system requirements, the fault diagnosis application program is designed by using modules. It includes the system selftest module, performance test operation module, system device drive module, data management module, fault diagnosis module. The flow chart and transfer principle frame of the program is shown in Fig.1.

\section{Key TECHNIQUES}

\section{A. Establishment of Knowledge Database}

Expert system is an intelligent program system; it can solve the special field questions by imitating the human experts. It can deduce and judge the faults by the knowledge and experience of experts of some fields, and it can solve those complex questions that need be solved by experts.

So:

Expert system $=$ Knowledge database + Illation techniques.

Thus, the knowledge database is established in this system.

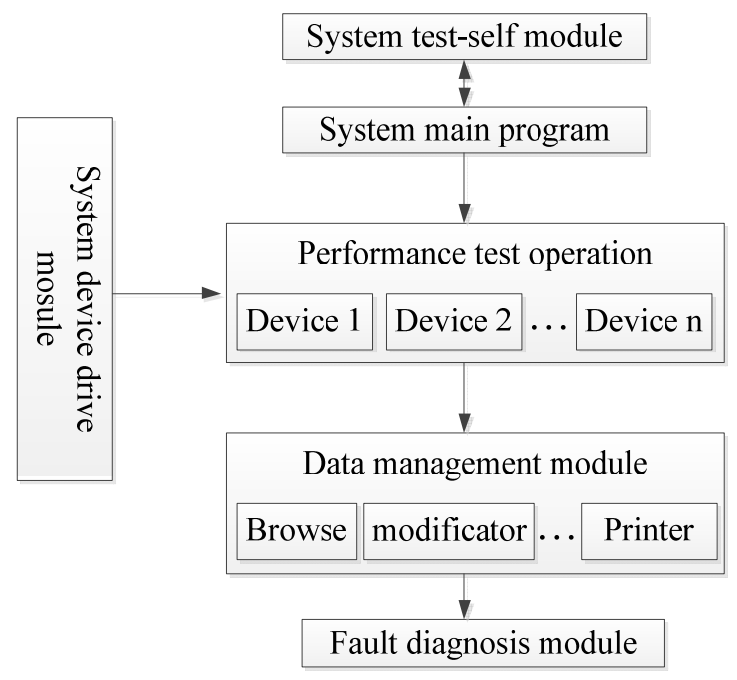

Figure 1. The flow chart and transfer principle frame.

The resources of knowledge database are from the structure function knowledge and the expert heuristic experience knowledge. That is deep knowledge and shallow knowledge. Deep knowledge mainly includes the structure, function of electro-device, the relation of input and output and the work principle of the electron-device itself and so on. Shallow knowledge mainly includes some direct interdependent rules and these rules can show fault, sign, and reason etc. Lots of useful diagnosis maintenance experience and fault cases are accumulated in the fault diagnosis and maintenance of the airborne electron-device. They can be got together and packed up as rules or special fault cases, and then the rule database is established [6-7].

In order to improve the process speed of the system, the multidimensional relation table is used to organize and memory the fault diagnosis rules. It is shown in the Table I.

In Table I, each row corresponds to one diagnosis rule of the expert system knowledge database. For example, there are $\mathrm{n}$ selected test parameters of board card and circuitry, they correspond to the test parameters $\left(C_{1} \sim C_{2}\right)$, there may be $\mathrm{m}$ fault causes in the system, they accord to the fault cause $Y_{1} \sim Y_{\mathrm{n}}$ in Table $\mathrm{I}$. The data of the $i$ th row of the Table I represent certain combination of every test parameter, and describe the relationship between those test parameters and each fault cause.

TABLE I. The MUltidimENSIONAL RELATIONS OF THE FAUlt DIAGNOSIS RULES

\begin{tabular}{|c|c|c|c|c|c|c|}
\hline \multirow{2}{*}{ Serial number } & \multicolumn{3}{|c|}{ Test parameter } & \multicolumn{3}{|c|}{ Fault cause } \\
\hline & $C_{1}$ & $\ldots$ & $C_{n}$ & $Y_{1}$ & $\ldots$ & $\boldsymbol{Y}_{m}$ \\
\hline 1 & $\alpha_{11}$ & $\ldots$ & $\alpha_{\ln }$ & $\beta_{11}$ & $\ldots$ & $\beta_{1 \mathrm{~m}}$ \\
\hline 2 & $\alpha_{21}$ & $\ldots$ & $\alpha_{2 n}$ & $\beta_{21}$ & $\ldots$ & $\beta_{2 \mathrm{~m}}$ \\
\hline ! & i & i & i & ! & ! & ! \\
\hline I & $\alpha_{i 1}$ & $\alpha_{i j}$ & $\alpha_{\text {in }}$ & $\beta_{\text {i1 }}$ & $\beta_{\mathrm{ik}}$ & $\beta_{\text {im }}$ \\
\hline \begin{tabular}{|l}
$!$ \\
$\vdots$
\end{tabular} & i & i & 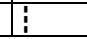 & i & 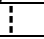 & ; \\
\hline
\end{tabular}

In Table I : 

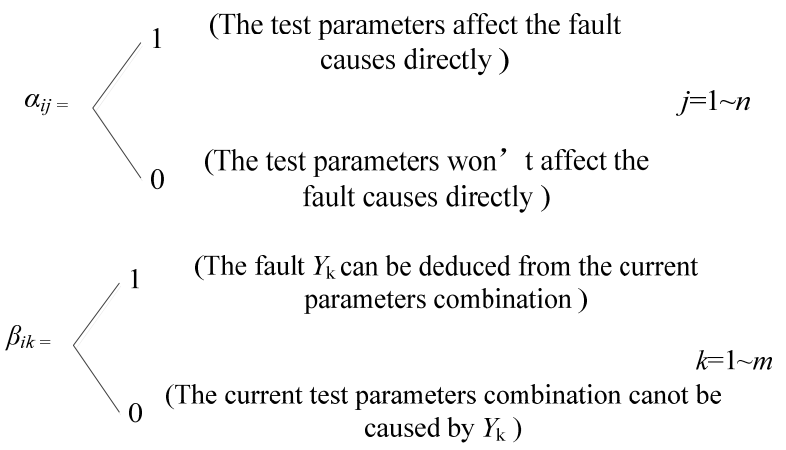

\section{B. Fault Converse Illation Technique}

Nowadays the method of fault isolation in the fault diagnosis system is commonly to begin from "symptom" and find fault part by using certain illation technique. The key point of it is to find general illation technique. The technique is propitious to the select "symptom" aggregate and achieves fault isolation purpose. But such general illation technique is hard to find in the fault isolation of radio compass. Because the information categories of the "symptom" aggregate are various and they are connected with each other, moreover, lots of signal actuating points and test points of isolation fault cannot be obtained from the sockets, so fault coupling and indeterminacy will happen. For example, in the electric module, there are more than 200 test points, 11 pieces of pin board and affiliated circuit, the circuit principle and work method of each pin board are different. It's hard to deal with so many "symptom" by using single method. So the fault converse illation technique is put forward.

Fault converse illation technique: The first is to assure the board and circuitry that is good or not, that is to isolate the part beforehand; the second is to test each item, then diagnose by using proper fault diagnosis method after test. These methods are selected out during the analysis phase; they are proved by some instances. So they have strong pertinence. The fault converse illation technique is shown in Fig.2.

\section{Application of ANN in Hydraulic Pressure CONTROL SYSTEM}

The hydraulic pressure control system is composed of the oil jar, the piston, the hermetic components, the oil pump, the flooding valves, the unilateral valves and the commutator valves. The input signals are provided by control rule, the output signals obtained by linear displacement sensor of the main oil jar. Actually, the hydraulic pressure controller is high step nonlinear tache, whose math model is composed of the binary tache, velocity limitation tache and the location limitation tache. Some kind hydraulic pressure control system mode is shown in Fig. 3.

There are five kinds of typical faults in such hydraulic pressure control system. They are as follow:

- The hermetic component of the main oil jar is disabled, The oil jar are leaking badly;

- The oil pump is disabled, the oil supply is deficiency;
- The flooding valves suffer a lot of wear and tear, they work badly;

- The core of the commutator valve suffers a lot of wear and tear, they can't move to the preconcerted place;

- The unilateral valves can't be closed tightly.

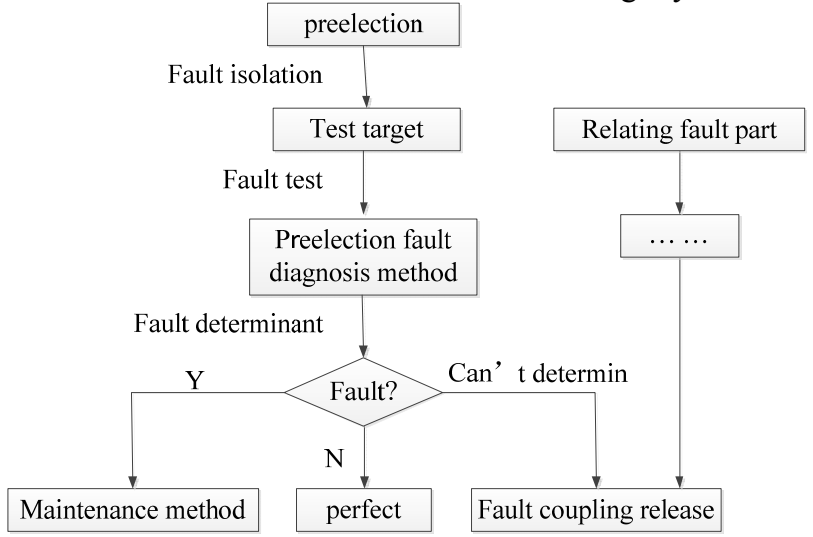

Figure 2. Fault converse illation technique.

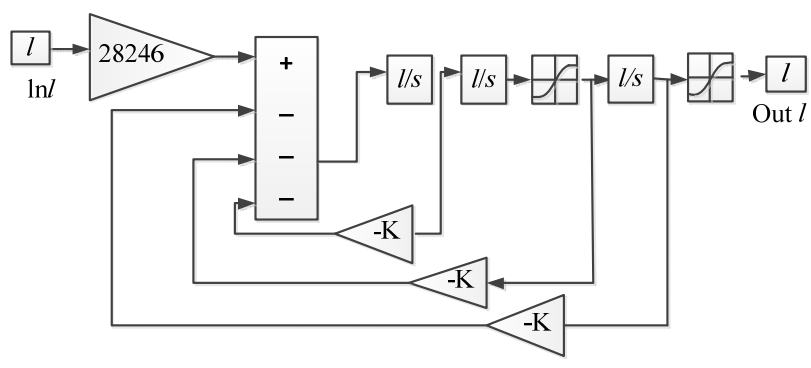

Figure 3. Some kind hydraulic pressure controller mode.

In the hydraulic pressure controller faults diagnosis system, a fault $F_{\mathrm{j}}$ may possibly related to many samples; however a certain fault symptom $X_{\mathrm{i}}$ may be treated as dim term of many samples. The complex relationship between symptoms and faults is incarnated in the whole network which is composed of many samples set. So the three feedback neural network which has relatively mature technology is used as the topology structure of faults diagnosis network [7].

In order to test the diagnosis capacity of network, the faults are diagnosed though three groups of data. The diagnosis results are shown in Table II.

TABLE II. The FaUlts Diagnosis Results

\begin{tabular}{|l|l|l|l|l|l|l|}
\hline \multirow{2}{*}{$\begin{array}{c}\text { Sample } \\
\text { number }\end{array}$} & \multirow{2}{*}{$\begin{array}{c}\text { Faults } \\
\text { types }\end{array}$} & \multicolumn{5}{|c|}{ Diagnosis results } \\
\cline { 3 - 7 } & & Fault 1 & Fault 2 & $\begin{array}{c}\text { Fault } \\
\mathbf{3}\end{array}$ & $\begin{array}{c}\text { Fault } \\
\mathbf{4}\end{array}$ & Fault 5 \\
\hline 1 & Fault 1 & 1.0262 & -0.0356 & -0.026 & 0.1185 & 0.039 \\
\hline 2 & Fault 2 & -0.5175 & 1.4797 & 0.037 & -0.212 & 0.0071 \\
\hline 3 & Fault 3 & 0.08631 & -0.0029 & 0.9138 & -0.136 & 0.463 \\
\hline 4 & Fault 4 & -0.432 & 0.0026 & 0.0068 & 1.7592 & -0.0612 \\
\hline 5 & Fault 5 & 0.3548 & -0.0172 & 0.0062 & 0.0532 & 1.2638 \\
\hline
\end{tabular}




\section{CONCLUSIONS}

Aimed at the typical faults of some kind hydraulic pressure control system, the three feedback artificial neural network structure is introduced, the conjugate grads BP arithmetic and its programme process are presented; many advanced techniques such as knowledge database and fault converse illation Technique are applied in the hydraulic pressure control fault diagnosis system. The diagnosis results illustrate that the ANN has high faults isolation capacity, and can recognize three feature types of faults exactly. Compared to the old diagnosis method, the new diagnosis technique has many advantages such as higher faults diagnosis efficiency and veracity, better diagnosis isolation capacity.

\section{REFERENCES}

[1] Yao Zhi-gang, Fu Qiang and Wu Bo-mao, "Design of Testing Platform for Fault Diagnosis of one New Equipment," Measurement and Control Technology, vol. 25, no. 4, 2009, pp. 30-32.
[2] H. X. Liu, H. T. Yu, M. Q. Hu, L. Huang and L. Yu, "Acceleration Compensating Fuzzy Control in Magnetic Suspension System," Proc. Advanced Materials Reseach. TRANS TECH PUBLICATIONS, March 2012, pp. 64-68.

[3] Liu Rong, Zhou Mingqi, "Fault and diagnosis expert system summarization," Measurement and Control Technology, vol. 13, no. 5, 2008, pp. 6-9.

[4] Ishibuchi H and Nii M, "Numerical analysis of the learning of fuzzified neural networks forms fuzzy if-then rules," Fuzzy sets and Systems, vol. 120, no. 10, 2010, pp. 281-307.

[5] X. Y. Zhang and J. F. Fan, "Design of auto-Detection Instrument for Airborne Thermometer System," Proc. Advanced Materials Reseach. TRANS TECH PUBLICATIONS, March 2012, pp. 875-878.

[6] Wang Mei and Wen Caifeng, "Modeling and Simulation of Off-grid Wind Power System Based on Matlab," China Measurement and Test, vol. 38, no. 6, 2012, pp. 91-95.

[7] Xu Bihua, Li Jian, Liang Dachuan and Wang Yujian, "Research of Fuzzy Comprehensive Evaluation Model for Displacement Efficiency of Cementing," Proc. IEEE Computer Society, IEEE Press, July 2010, pp. 381-384. 